\title{
Erratum to: The effects of probiotics on depressive symptoms in humans: a systematic review
}

Caroline J. K. Wallace ${ }^{*}$ and Roumen Milev

\section{Erratum to: Ann Gen Psychiatry (2017) 16:14 DOI 10.1186/s12991-017-0138-2}

The original article [1] has been updated to include the correct version of Table 1 . The article originally published online showed an incomplete version of the table. The correct version of Table 1 is shown in this erratum. This error was carried forward by the production team and was not the fault of any authors. 


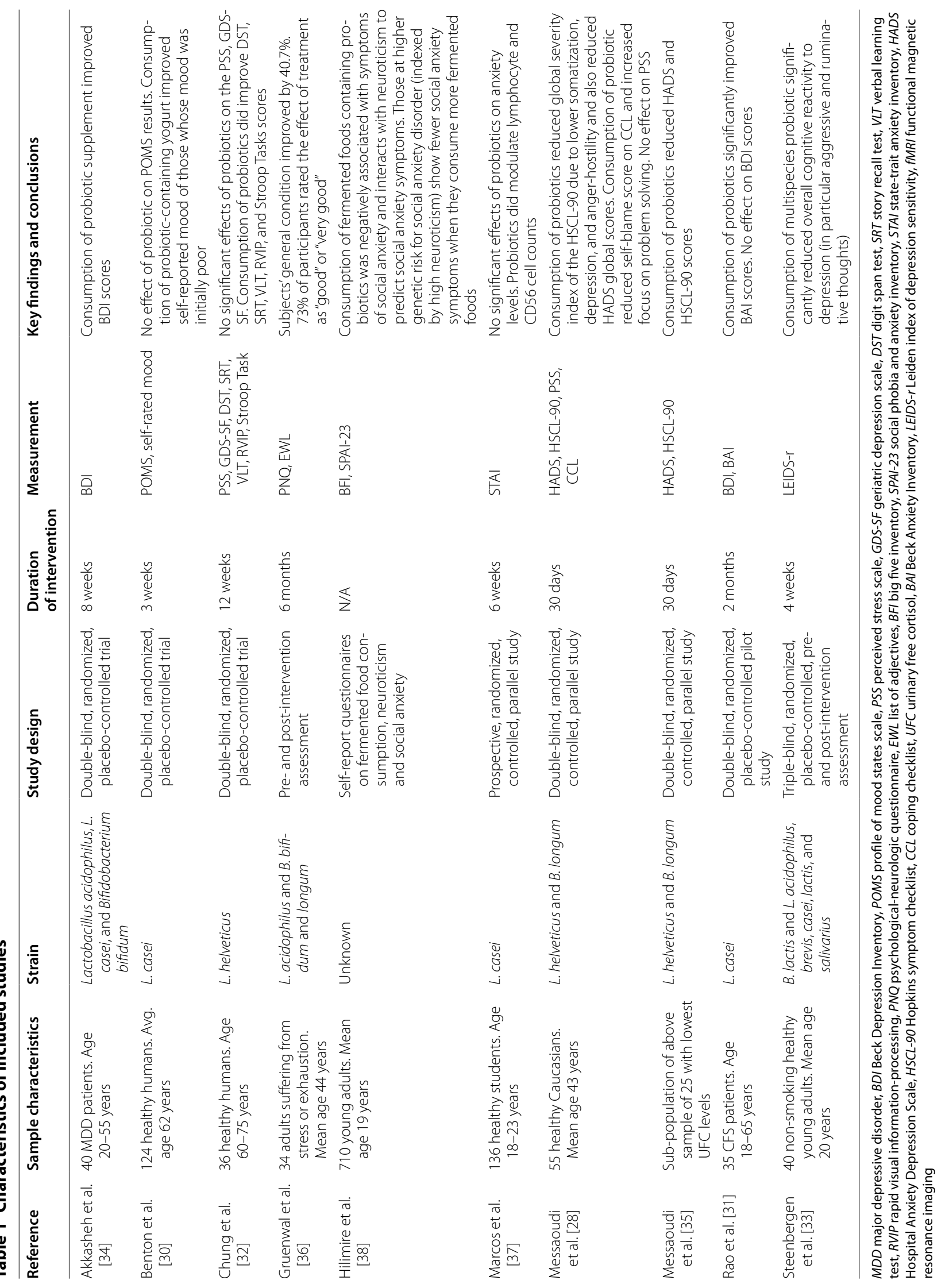


The online version of the original article can be found under doi:10.1186/s12991-017-0138-2.

Received: 24 February 2017 Accepted: 27 February 2017

Published online: 07 March 2017

\section{Reference}

1. Wallace CJK, Milev Roumen. The effects of probiotics on depressive symptoms in humans: a systematic review. Ann Gen Psychiatry. 2017;16:14. doi:10.1186/s12991-017-0138-2. 